\title{
As tecnologias educacionais em saúde na promoção e proteção do aleitamento materno
}

\author{
Health educational technologies in the promotion and protection of breastfeeding
}

Tecnologías educativas en salud en la promoción y protección de la lactancia materna

Rodrigo Monteiro Gomes de Moura ${ }^{1 *}$, Ubiratan Ribeiro Martins Neto.

\begin{abstract}
RESUMO
Objetivo: Compreender as contribuições das tecnologias educacionais em saúde relacionadas a promoção e proteção do aleitamento materno. Métodos: Este estudo constitui-se uma revisão integrativa de literatura com delineamento descritivo. A seleção dos artigos foi realizada no portal de buscas da Biblioteca Eletrônica Científica Online (SCIELO) e Biblioteca Virtual de Saúde (BVS) no mês de abril de 2020. Resultados: Após a seleção completa dos artigos nas bases de dados supracitadas, foram utilizados 13 artigos nesse estudo. A língua portuguesa predominou em doze estudos $(92,3 \%)$ e um artigo $(7,7 \%)$ estava em inglês. O ano de publicação prevalente foi 2018 com cinco artigos (38,5\%), seguido por 2019 com três artigos (23,1\%) e 2015 com dois artigos (15,4\%) e 2016 e 2017 com um artigo (7,7\%) cada. Considerações finais: $O$ estudo desvelou que as tecnologias educacionais em saúde estão imbricadas no desenvolvimento de processos educativos, facilitando assim o diálogo entre o profissional de saúde e o público-alvo.
\end{abstract}

Palavras-chave: Aleitamento materno, Tecnologia educacional, Educação em saúde.

\section{ABSTRACT}

Objective: To understand how contributions of educational health technologies related to the promotion and protection of breastfeeding. Methods: This study constitutes an integrative literature review of descriptive type. The selection of articles was carried out on the search portal of the Scientific Electronic Library Online (SCIELO) and Virtual Health Library (BVS) in April 2020. Results: After the complete selection of articles in the databases, 13 articles were used in this study. The Portuguese language predominated in twelve studies $(92,3 \%)$. One of them $(7,7 \%)$ were in English language. The prevalent publication year was 2018 with five articles (38.5\%), followed by 2019 with three articles (23.1\%) and 2015 with two articles (15.4\%) and 2016 and 2017 with one article $(7,7 \%)$ each. Final considerations: The study revealed that educational health technologies are involved in the development of educational processes, facilitating the dialogue between the health professional and the target audience.

Keywords: Breast feeding, Educational technology, Health education.

\section{RESUMEN}

Objetivo: Comprender cómo los aportes de las tecnologías educativas en salud se relacionan con la promoción y protección de la lactancia materna. Métodos: Este estudio constituye una revisión integradora de la literatura de tipo descriptivo. La selección de artículos se realizó en el portal de búsqueda de la Biblioteca Electrónica Científica en Línea (SCIELO) y Biblioteca Virtual en Salud (BVS) en abril de 2020. Resultados: Luego de la selección completa de artículos en las bases de datos, se utilizaron 13 artículos en este estudiar. El idioma portugués predominó en doce estudios (92,3\%). Uno de ellos $(7,7 \%)$ estaban en idioma inglés. El año de publicación predominante fue 2018 con cinco artículos (38,5\%), seguido de 2019 con tres artículos (23,1\%) y 2015 con dos artículos (15,4\%) y 2016 y 2017 con un artículo $(7,7 \%)$ cada uno. Consideraciones finales: El estudio reveló que las tecnologías educativas en salud están involucradas en el desarrollo de los procesos educativos, facilitando el diálogo entre el profesional de la salud y el público objetivo.

Palabras clave: Lactancia materna, Tecnología educacional, Educación en salud.

${ }^{1}$ Centro Universitário da Grande Dourados (UNIGRAN), Dourados - MS.

*E-mail: rodrigomoura291@hotmail.com

SUBMETIDO EM: 8/2020

ACEITO EM: 9/2020

PUBLICADO EM: 10/2020 


\section{INTRODUÇÃO}

O aleitamento materno exclusivo até o sexto mês de vida, pode prevenir cerca de 823.000 mortes de crianças menores de cinco anos e 20.000 mortes em mulheres por câncer de mama a cada ano, porém nos países subdesenvolvidos apenas $37 \%$ das crianças são exclusivamente amamentadas até o sexto mês de vida (VICTORA CG, et al., 2016).

A amamentação é um processo de suma importância para o recém-nascido, pois sua prática proporciona vínculo, afeto, proteção e nutrição para a criança, além de ser a forma de alimentação mais antiga, econômica e eficiente na redução da morbimortalidade infantil (BRASIL, 2015).

No entanto, observa-se que as mães se sentem inexperientes e inseguras. Além disso, o tempo despendido a profissão, as crenças pessoais, algumas influências de terceiros e a falta de uma rede de apoio corroboram para o abandono do aleitamento materno (CAPUCHO LB et al., 2017).

Sendo assim, torna-se relevante o uso das tecnologias educacionais, visto que podem contribuir com a promoção e proteção do aleitamento materno por possibilitarem a ampliação do acesso à informação e também oferecerem um apoio as mães e cuidadores. O resultado esperado é o aumento das taxas de adesão a essa prática (VASCONCELOS MGL, et al., 2013).

Ademais, as tecnologias educativas podem ser usadas como estratégias que permitem a potencialização da educação em saúde, uma vez que proporcionam aos educandos maior aproximação com o tema trabalhado. Além de, possibilitarem a participação ativa das pessoas na assimilação real do conhecimento (SANTOS AS, et al., 2018).

Nesse sentido, as tecnologias educacionais favorecerem a elevação do nível de conhecimento e confiança da população, dando-lhes a base e suporte para a realização do autocuidado. Além disto, contribuem no processo de comunicação e interação entre o profissional da saúde e a comunidade, com vista a incentivar os hábitos de vida saudáveis (BARBOSA EMG, et al., 2016).

O crescimento das tecnologias educacionais em saúde vem com a finalidade de auxiliar no processo de entendimento de conteúdos e melhorias metodológicas para procedimentos de educação em saúde e diálogo com a comunidade (TEIXEIRA EM e SOUZA VMS, 2011).

Diante o exposto, verifica-se a relevância do aleitamento materno e as contribuições das tecnologias educacionais em saúde junto à comunidade, com vistas a tornar eficaz o processo de ensino-aprendizagem e fortalecer os hábitos de vida saudáveis. Deste modo, o presente estudo tem como objetivo compreender as contribuições das tecnologias educacional em saúde relacionadas a promoção e proteção do aleitamento materno.

\section{MÉTODOS}

Trata-se de um estudo de revisão integrativa da literatura e com delineamento descritivo. Buscou-se identificar, agrupar, avaliar e sintetizar os conhecimentos científicos disponíveis sobre o tema pesquisado. Para nortear os objetivos da presente pesquisa emergiram duas questões: Quais os tipos de tecnologias educacionais têm sido produzidos para promover o aleitamento materno? Como as tecnologias educacionais têm contribuído na promoção do aleitamento materno?

A seleção dos artigos foi realizada no portal de buscas da Biblioteca Eletrônica Científica Online (SCIELO) e Biblioteca Virtual de Saúde (BVS) no mês de abril de 2020. Para a busca foram utilizados os seguintes descritores de ciências da saúde (DECS) combinados com o operador booleano and: "tecnologia educacional" and "aleitamento materno; "tecnologia" and "aleitamento materno"; "educação em saúde" and "aleitamento materno"; "Educational Technology" and "Breast Feeding".

Como critérios de inclusão buscou-se por artigos que retratavam sobre a aplicação de tecnologias educacionais na promoção do aleitamento materno nas línguas portuguesa e inglesa. Os critérios de exclusão foram estudos que antecederam o ano de 2015 e artigos de revisão. A priori foram encontrados 955 artigos, a partir dos descritores anteriormente relatado, sendo refinado o corte para artigos publicados nos últimos 5 anos, em língua inglesa e portuguesa restando assim 296 artigos. 
Posteriormente, foi realizado a leitura dos títulos e resumos dos 296 artigos é pré-selecionados os estudos que correspondiam aos objetivos da presente pesquisa que totalizaram 24 . No terceiro momento foi realizado a leitura completa dos 24 artigos, sendo selecionados ao final 13 artigos. Foram incluídos artigos que representavam em seus resultados os objetivos desse estudo e seus respectivos critérios.

Com seleção completa dos artigos, utilizados nesse estudo, foram extraídos os seguintes dados: título das pesquisas; autores; métodos das pesquisas; tipos de tecnologia educacional; e resultados da aplicação das tecnologias educacionais.

\section{RESULTADOS E DISCUSSÃO}

Após a seleção completa dos artigos nas bases de dados supracitadas, foram utilizados 13 artigos nesse estudo. A Figura 1, apresentada a seguir, demonstra o processo de seleção dos artigos a partir dos objetivos, critérios de inclusão e exclusão e as combinações entre descritores que foram utilizados nessa pesquisa.

Figura 1 - Fluxograma de seleção dos artigos.

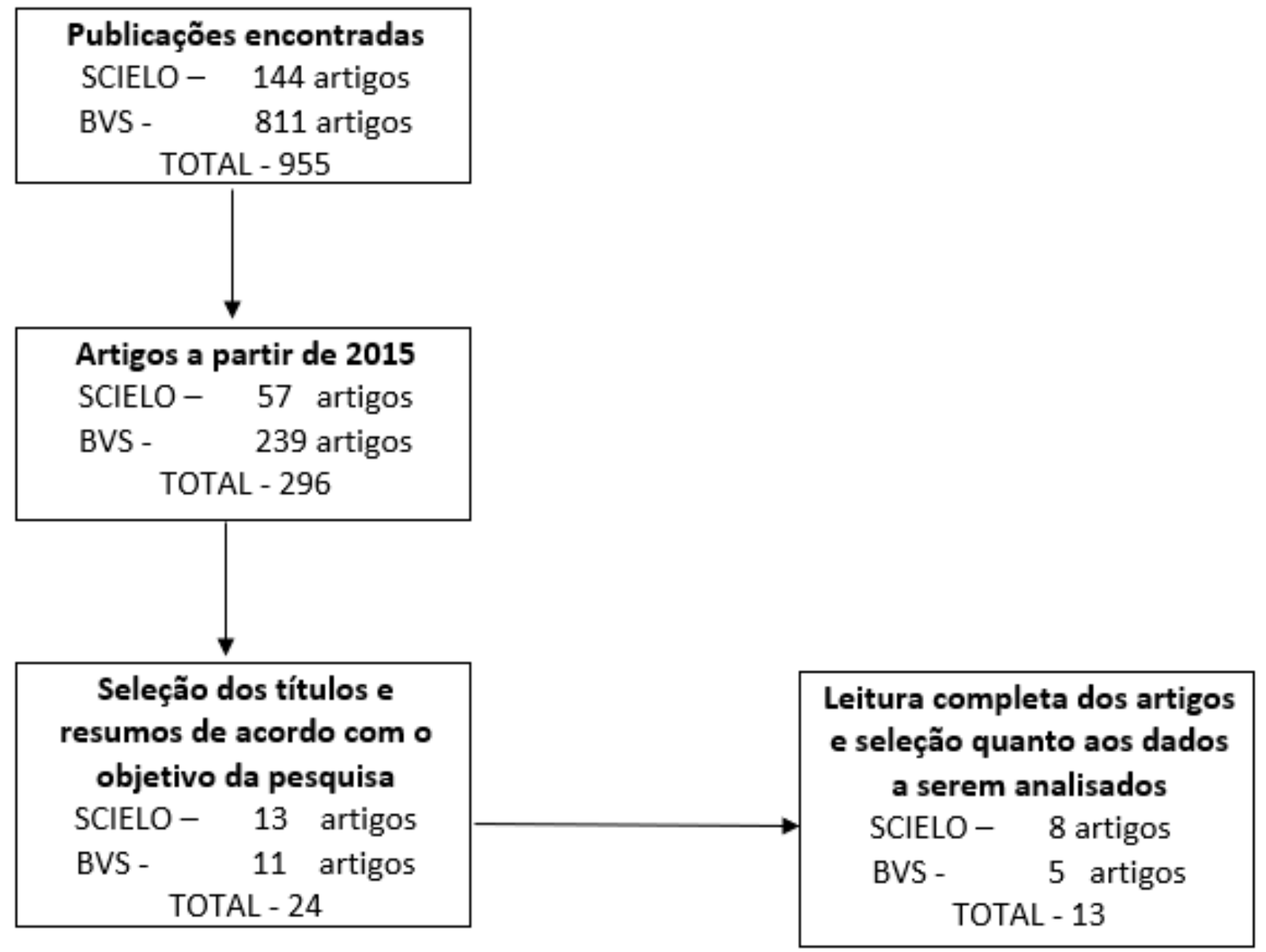

Fonte: Moura RMG e Martins Neto UR, 2020. Dados extraídos da BVS e SCIELO.

A Figura 1, mostra que nos artigos selecionados, oito $(61,5 \%)$ foram identificados no portal Scielo, cinco (38.5\%) na base de dados BVS. A língua portuguesa predominou em doze estudos (92,3\%) e um artigo (7,7\%) estavam em inglês.

O ano de publicação prevalente foi 2018 com cinco artigos (38,5\%), seguido por 2019 com três artigos $(23,1 \%)$ e $2015 \mathrm{com}$ dois artigos (15,4\%) e 2016 e $2017 \mathrm{com}$ um artigo (7,7\%) cada. A seguir serão apresentados, no Quadro 1, os dados coletados nos 13 artigos (100\%) selecionados, caracterizando-os quanto aos autores, ano de publicação, objetivo da pesquisa, tipo de tecnologia educativa e respectivo público-alvo. 


\section{Revista Eletrônica Acervo Saúde / Electronic Journal Collection Health | ISSN 2178-2091}

Quadro 1 - Panorama dos Estudos Selecionados no Portal Scielo e Base de Dados BVS.

\begin{tabular}{|c|c|c|c|c|c|c|}
\hline № & Autores/ano & Título do Artigo & Objetivo do estudo & $\begin{array}{l}\text { Tecnologia } \\
\text { educacional }\end{array}$ & Método & Público-alvo \\
\hline 1 & $\begin{array}{l}\text { Cherubim } \\
\text { DO, et al. } \\
(2019)\end{array}$ & $\begin{array}{l}\text { Tecnologia educativa musical para } \\
\text { aprendizagem da fisiologia da } \\
\text { lactação : tradução do conhecimento }\end{array}$ & $\begin{array}{l}\text { Desenvolver e validar um } \\
\text { processo educativo por meio } \\
\text { de música. }\end{array}$ & Música & $\begin{array}{c}\text { Estudo metodológico com aplicação de } \\
\text { Modelo Conceitual de Tradução do } \\
\text { Conhecimento. }\end{array}$ & $\begin{array}{l}\text { Acadêmicos } \\
\text { da Área da } \\
\text { Saúde }\end{array}$ \\
\hline 2 & $\begin{array}{l}\text { Martins FDP, } \\
\text { et al. (2018) }\end{array}$ & $\begin{array}{l}\text { Efeito de tecnologia educacional jogo } \\
\text { de tabuleiro no conhecimento de } \\
\text { escolares sobre aleitamento materno }\end{array}$ & $\begin{array}{l}\text { Avaliar o efeito do jogo } \\
\text { educativo com tabuleiro. }\end{array}$ & Jogos & $\begin{array}{c}\text { Ensaio clínico randomizado por } \\
\text { conglomerado. }\end{array}$ & $\begin{array}{l}\text { Crianças } \\
\text { Ensino } \\
\text { Fundamental }\end{array}$ \\
\hline 3 & $\begin{array}{l}\text { Javorski M, } \\
\text { et al. (2018) }\end{array}$ & $\begin{array}{c}\text { Efeitos de uma tecnologia educativa } \\
\text { na autoeficácia para amamentar e na } \\
\text { prática do aleitamento materno } \\
\text { exclusivo }\end{array}$ & $\begin{array}{l}\text { Avaliar os efeitos do } \\
\text { processo educativo por meio } \\
\text { de álbum seriado. }\end{array}$ & $\begin{array}{l}\text { Álbum } \\
\text { seriado }\end{array}$ & $\begin{array}{l}\text { Estudo de intervenção, controlado e } \\
\text { randomizado. }\end{array}$ & Gestantes \\
\hline 4 & $\begin{array}{l}\text { Dodt RCM, et } \\
\text { al. (2015) }\end{array}$ & $\begin{array}{c}\text { Estudo experimental de uma } \\
\text { intervenção educativa para promover } \\
\text { a autoeficácia materna na } \\
\text { amamentação }\end{array}$ & $\begin{array}{l}\text { Construir, validar e avaliar o } \\
\text { Processo educativo por meio } \\
\text { de flip-chart (portfólio). }\end{array}$ & Flip-chart & Estudo experimental & Puérperas \\
\hline 5 & $\begin{array}{c}\text { Oliveira } \\
\text { PMP, et al. } \\
(2017)\end{array}$ & $\begin{array}{l}\text { Amamentação: validação de } \\
\text { tecnologia assistiva em áudio para } \\
\text { pessoa com deficiência visual }\end{array}$ & $\begin{array}{l}\text { Validar o processo educativo } \\
\text { por meio de áudio através do } \\
\text { acesso online. }\end{array}$ & Áudio & $\begin{array}{l}\text { Pesquisa de desenvolvimento } \\
\text { metodológico em que se adotou modelo } \\
\text { da Psicometria, constituído dos polos } \\
\text { teórico, empírico e analítico. }\end{array}$ & $\begin{array}{l}\text { Pessoas com } \\
\text { Deficiência } \\
\text { Visual }\end{array}$ \\
\hline 6 & $\begin{array}{l}\text { Nunes RD, et } \\
\text { al. (2019) }\end{array}$ & $\begin{array}{l}\text { Evaluating the effectiveness of an } \\
\text { educative workshop for pregnant } \\
\text { women using pre and post } \\
\text { intervention surveys }\end{array}$ & $\begin{array}{l}\text { Validar o processo educativo } \\
\text { por meio de roda de } \\
\text { conversa (oficina). }\end{array}$ & $\begin{array}{l}\text { Roda de } \\
\text { Conversa }\end{array}$ & Estudo transversal. & Gestantes \\
\hline 7 & $\begin{array}{l}\text { Ribeiro NM, } \\
\text { et al. (2018) }\end{array}$ & $\begin{array}{l}\text { Construção e validação de folheto } \\
\text { educativo para promoção do } \\
\text { aleitamento materno e alimentação } \\
\text { complementar do lactente }\end{array}$ & $\begin{array}{l}\text { Descrever e validar o } \\
\text { processo educativo por meio } \\
\text { de folheto educativo. }\end{array}$ & $\begin{array}{l}\text { Folheto } \\
\text { Educativo }\end{array}$ & Estudo observacional descritivo. & $\begin{array}{l}\text { Cuidadores } \\
\text { de RN e } \\
\text { Lactentes }\end{array}$ \\
\hline
\end{tabular}

REAS/EJCH | Vol.12(10) | e5058 | DOI: https://doi.org/10.25248/reas.e5058.2020 Página 4 de 10 
Revista Eletrônica Acervo Saúde / Electronic Journal Collection Health | ISSN 2178-2091

\begin{tabular}{|c|c|c|c|c|c|c|}
\hline № & Autores/ano & Título do Artigo & Objetivo do estudo & $\begin{array}{l}\text { Tecnologia } \\
\text { educacional }\end{array}$ & Método & Público-alvo \\
\hline 8 & $\begin{array}{l}\text { Medeiros } \\
\text { AMC, et al. } \\
\text { (2015) }\end{array}$ & $\begin{array}{l}\text { Aleitamento materno e aspectos } \\
\text { fonoaudiológicos: conhecimento e } \\
\text { aceitação de mães de uma } \\
\text { maternidade }\end{array}$ & $\begin{array}{l}\text { Investigar o conhecimento } \\
\text { das puérperas sobre } \\
\text { amamentação e verificar a } \\
\text { aceitação sobre a } \\
\text { intervenção grupal realizada. }\end{array}$ & $\begin{array}{l}\text { Roda de } \\
\text { Conversa }\end{array}$ & Estudo intervencionista e comparativo. & Puérperas \\
\hline 9 & $\begin{array}{l}\text { Abissulo } \\
\text { CMF, et al. } \\
(2016)\end{array}$ & $\begin{array}{c}\text { Validação de simuladores realísticos } \\
\text { para orientação sobre aleitamento } \\
\text { materno: pesquisa quase- } \\
\text { experimental }\end{array}$ & $\begin{array}{l}\text { Validar o processo educativo } \\
\text { por meio de simuladores } \\
\text { realísticos de baixa } \\
\text { fidelidade. }\end{array}$ & Simuladores & $\begin{array}{l}\text { Pesquisa exploratória, transversal, de } \\
\text { abordagem quantitativa e qualitativa. }\end{array}$ & Puérperas \\
\hline 10 & $\begin{array}{l}\text { Freitas LA, et } \\
\text { al. (2018) }\end{array}$ & $\begin{array}{l}\text { Avaliação do curso online na } \\
\text { educação permanente sobre } \\
\text { aleitamento materno para } \\
\text { enfermeiros }\end{array}$ & $\begin{array}{c}\text { Avaliar o processo educativo } \\
\text { realizado através curso } \\
\text { online. }\end{array}$ & Curso Online & $\begin{array}{c}\text { Pesquisa quantitativa, descritiva e } \\
\text { transversal }\end{array}$ & Enfermeiros \\
\hline 11 & $\begin{array}{l}\text { Sardinha } \\
\text { DM, et al. } \\
(2019)\end{array}$ & $\begin{array}{l}\text { Promoção do aleitamento materno na } \\
\text { assistência pré-natal pelo enfermeiro }\end{array}$ & $\begin{array}{l}\text { Realização de processo } \\
\text { educativo realizado através } \\
\text { de um jogo de perguntas. }\end{array}$ & Jogos & $\begin{array}{l}\text { Estudo qualitativo, descritivo, tipo relato } \\
\text { de experiência. }\end{array}$ & Gestantes \\
\hline 12 & $\begin{array}{l}\text { Silva DRS, et } \\
\text { al. (2019) }\end{array}$ & $\begin{array}{l}\text { Oficina sobre aleitamento materno } \\
\text { com agentes comunitários de saúde: } \\
\text { do saber ao aprendizado }\end{array}$ & $\begin{array}{c}\text { Avaliar o impacto do } \\
\text { processo educativo por meio } \\
\text { de oficina de atualização. }\end{array}$ & $\begin{array}{l}\text { Roda de } \\
\text { Conversa }\end{array}$ & $\begin{array}{c}\text { Estudo transversal, descritivo- } \\
\text { exploratório, com abordagem } \\
\text { quantitativa. }\end{array}$ & $\begin{array}{l}\text { Agentes } \\
\text { Comunitários } \\
\text { em Saúde } \\
\text { (ACS) }\end{array}$ \\
\hline 13 & $\begin{array}{l}\text { Rodrigues } \\
\text { VO, et al. } \\
\text { (2018) }\end{array}$ & $\begin{array}{l}\text { O fazer profissional no codiano: } \\
\text { vivências de práticas educativas na } \\
\text { prevenção de intercorrências } \\
\text { mamárias que incentivam a } \\
\text { promoção do aleitamento materno. }\end{array}$ & $\begin{array}{l}\text { Relatar a experiência de } \\
\text { acadêmicos no processo de } \\
\text { educação em saúde } \\
\text { utilizando tecnologias } \\
\text { educativas. }\end{array}$ & $\begin{array}{l}\text { Cartaz, } \\
\text { Folder e } \\
\text { Molde }\end{array}$ & $\begin{array}{l}\text { Estudo descritivo do tipo relato de } \\
\text { experiência }\end{array}$ & Gestantes \\
\hline
\end{tabular}

Fonte: Moura RMG e Martins Neto UR, 2020. Dados extraídos da BVS e SCIELO.

REAS/EJCH | Vol.12(10) | e5058 | DOI: https://doi.org/10.25248/reas.e5058.2020 Página $\mathbf{5}$ de $\mathbf{1 0}$ 
Nota-se, que as tecnologias educacionais estão imbricadas no desenvolvimento de processos educativos, que discutiram acerca do aleitamento materno com usuárias dos sistemas de saúde, profissionais de saúde, acadêmicos da saúde e também estudantes da rede básica de ensino.

Ademais, pode-se observar no Quadro 1, que os métodos predominantes se constituíram: pesquisa descritiva com quatro estudos $(30,8 \%)$, estudo transversal com três estudos $(23,1 \%)$, pesquisa metodológica com dois estudos $(15,4 \%)$ e estudo de intervenção com dois estudos $(15,4 \%)$. Dando continuidade na caracterização dos estudos coletados, a seguir serão apresentados os dados referentes ao público-alvo das tecnológicas educacionais analisadas no portal Scielo e base de dados BVS na Tabela 1.

Tabela 1 - Público Alvo.

\begin{tabular}{lcc}
\hline Público alvo & N & $\%$ \\
\hline Gestantes & 4 & 30,8 \\
Puérperas & 3 & 23,1 \\
Enfermeiros & 1 & 7,7 \\
Agente Comunitário em Saúde & 1 & 7,7 \\
Acadêmicos área da saúde & 1 & 7,7 \\
Pessoas com deficiência visual & 1 & 7,7 \\
Crianças Ensino Fundamental & 1 & 7,7 \\
Cuidadores de RN e Lactentes & 1 & 7,7 \\
\hline
\end{tabular}

Fonte: Moura RMG e Martins Neto UR, 2020. Dados extraídos da BVS e SCIELO.

No tocando ao público-alvo, os artigos coletados evidenciam o predomínio de gestantes, sendo notado a presença em quatro estudos ( $30,8 \%)$, seguido pelas puérperas em três estudos $(23,1 \%)$ e enfermeiros, agente comunitário em saúde (ACS), discentes área da saúde, pessoas com deficiência visual, crianças do ensino fundamental e cuidadores de recém-nascido (RN) e lactentes em um artigo cada público respectivamente.

Deste modo, os estudos coletados por meio do portal Scielo e base de dados BVS, evidenciaram um predomínio de tecnologias educacionais voltadas para usuárias (gestantes e puérperas) do sistema de saúde que estão amamentando ou futuras lactentes, sendo representados por sete artigos (53,9\%). Ainda, na descrição dos estudos selecionados, a seguir serão evidenciados os tipos de tecnologia educacionais em saúde por meio da Tabela 2.

Tabela 2 - Tipos de Tecnologia Educacionais.

\begin{tabular}{llc}
\hline Tipos de tecnologia & N & $\%$ \\
\hline Tecnologias Impressas & 4 & 30,8 \\
Roda de Conversa & 3 & 23,1 \\
Gamificação & 2 & 15,4 \\
Simuladores & 2 & 15,4 \\
Audio & 1 & 7,7 \\
Música & 1 & 7,5 \\
\hline
\end{tabular}

Fonte: Moura RMG e Martins Neto UR, 2020. Dados extraídos da BVS e SCIELO.

Nota-se, a prevalência das tecnologias educacionais impressas $(30,8 \%)$, sendo representadas por: álbum seriado $(7,7)$; folheto educativo (7,7); flip chart $(7,7)$; e cartaz e folder $(7,7)$. Ainda no que se refere ao tipo de tecnologia educativa, os artigos coletados também destacam a roda de conversa como tecnologia educacional, sendo recorrente sua presença em três estudos analisados $(23,1 \%)$, seguido pelos jogos e simuladores em duas pesquisas (15,4\%).

Além disso, foram identificadas pesquisas que utilizaram como tecnologia educacional em saúde a música em um estudo (7,7\%), áudio em um artigo (7,7\%), e curso online em uma pesquisa $(7,7 \%)$. Na análise dos tipos de tecnologias educacionais, torna-se relevante elucidar que todas foram aplicadas em processos educativos, sendo individuais em dois estudos (15,4\%) e em grupo em 11 estudos (84,6\%).

No estudo de Rodrigues VO, et al. (2018) foram identificados dois tipos de tecnologias educacionais, sendo as tecnologias impressas com cartas e folder e também simuladores com o molde em formas de mamas. Destaca-se que o áudio representado no estudo de Oliveira PMP, et al. (2017), trata-se de um tipo de tecnologia educacional inclusiva ou auditiva, uma vez que o público-alvo foram pessoas com deficiência visual. 
Dando continuidade na análise dos artigos selecionados notou-se as contribuições das tecnologias educacionais em relação ao incentivo da prática do aleitamento materno nos participantes dos processos educativos, em que estas foram aplicadas. Dessa forma, foram elaboradas duas categorias em relação as tecnologias educacionais em saúde na promoção do aleitamento materno: fortalecimento do aleitamento materno; e desenvolvimento do senso crítico-reflexivo.

O fortalecimento do aleitamento materno é de extrema importante, pois de acordo com Brasil (2014) o desmame precoce antes dos seis meses ainda é uma realidade que ocorre frequentemente. Segundo Brasil (2015) as crianças que são amamentadas exclusivamente até essa idade possuem maior desenvolvimento cognitivo quando comparadas as que não são amamentadas exclusivamente. No mais o aleitamento materno oportuniza que as crianças tenham uma alimentação rica em nutrientes, anticorpos e outros componentes necessários para o seu crescimento e desenvolvimento saudável (PAIM JSL, et al., 2018).

Diante dos inúmeros benefícios do aleitamento materno, é importante que se invista em processos educativos em saúde sobre esse tema junto as gestantes com vistas a atenuar as suas dúvidas e conscientiza-las em relação as crenças limitantes e mitos que promovam a abdicação da amamentação (GUIMARAES DS, et al., 2018). Desse modo as ações de educação em saúde e o uso de tecnologias educacionais que estão relacionadas ao aleitamento materno permitem que as lactentes e acompanhantes ampliem seus conhecimentos sobre o tema e ainda diminuam suas dificuldades referentes a amamentação (ABISSULO CMF, et al., 2015).

Para promover o aumento dos conhecimentos em relação ao aleitamento materno é importante valorizar o contexto em que os educandos do processo educativo estão inseridos, além de entender seus saberes prévios e ajudá-los a edificarem novos conhecimentos acerca da temática (BRASIL, 2015).

Pensado nas inúmeras dificuldades que os serviços de saúde apresentam para realizar as práticas educativas entre os profissionais de saúde e os usuários, a utilização das tecnologias educacionais contribuem para o dinamismo e superação de uma educação monótona e enfadonha (FONSECA LMM, et al., 2011).

Estudos apontam que a utilização de tecnologias educacionais por profissionais de saúde durante o cuidado com neonatos apresentou melhores resultados no desenvolvimento de conhecimentos e habilidades relacionados a saúde do recém-nascido (BALBINO AC, et al., 2020).

\section{Fortalecimento do Aleitamento Materno}

Os processos educativos, dos estudos selecionados, conseguiram alcançar resultados satisfatório, uma vez que fortaleceram o aleitamento materno com a utilização das tecnologias educacionais em saúde. Observa-se que ocorreu a promoção e conscientização do público-alvo.

A tecnologia educacional que utilizou a gamificação, por meio de um jogo de tabuleiro, mostrou-se uma intervenção eficiente para aumentar o conhecimento de crianças sobre a temática amamentação. Para composição desse jogo educativo foi utilizado um tabuleiro, um dado, cinco pinos, 17 fichas de perguntas e um folheto explicativo apresentado a regra, desta forma foi estabelecido um espalho criativo e lúdico que aumentou os conhecimentos das crianças sobre aleitamento materno (MARTINS FDP, et al., 2018).

Da mesma forma, em uma pesquisa também desenvolvida, por meio de jogos educacionais de perguntas sobre os mitos que envolvem o processo de amamentar, proporcionou a troca de conhecimentos entre gestantes e a profissionais de saúde. Colaborando assim na promoção do aleitamento materno e ofertando condições para a execução da prática de amamentar. Esse estudo foi realizado com quinze gestantes e verificou-se que as gestantes acreditavam em muitos mitos que contribuem com as chances de desmame precoce, baixo peso e adoecimento da criança (SARDINHA DM, et al., 2019).

Da mesma forma, a utilização do álbum seriado, estruturado com sete ilustrações e suas respectivas fichas-roteiro, teve um resultado satisfatório no incentivo ao aleitamento materno exclusivo, resultando em uma probabilidade de amamentação exclusiva no grupo-intervenção (56 mulheres) de duas vezes maior do que no grupo-controle (56 mulheres) (JAVORSKI M, et al., 2018). 
Igualmente, o processo educativo realizado com um flip chart intitulado "Posso amamentar meu filho" obtiveram resultados proveitosos em relação ao aumento da aceitação ao aleitamento materno, bem como uma maior durabilidade da amamentação em dois meses após o parto. Essa pesquisa foi realizada com 201 mulheres no pós-parto, sendo 100 no grupo controle e 101 no grupo intervenção (DODT RCM, et al., 2015).

Semelhantemente, uma estratégia educacional mediada, por meio de áudio acesso online, manifestou-se válida para a promoção da saúde, possibilitando a compreensão do tema de uma forma simples. Além disso, o estilo de áudio foi capaz de causar impacto, motivação e interesse. Foi utilizada a literatura de cordel com 32 sextilhas apresentada em categorias, discutidas à luz dos referenciais teóricos pertinente ao tema aleitamento materno (OLIVEIRA PMP, et al., 2017).

Do mesmo modo, o folheto educativo desenvolvido por Ribeiro NM, et al. (2018), foi outra tecnologia educacional que se mostrou viável, pois, a linguagem, layout e ilustração que o compõem permite que se construa o conhecimento de forma didática e aumento o interesse pela temática. $O$ respectivo estudo foi desenvolvido com oito profissionais de saúde e 60 cuidadores de crianças menores de dois anos para a orientação do aleitamento materno e da alimentação complementar (RIBEIRO NM, et al., 2018).

Equitativamente um processo educativo utilizando a roda de conversa como estratégia de ensino, proporcionou as participantes puérperas, o acesso à informação, acolhimento e a criação de vínculo com os profissionais de saúde, além da promoção, proteção e o apoio ao aleitamento materno (MEDEIROS AMC, et al., 2015).

O estudo acima foi realizado com 163 puérperas, onde foi feito um teste de assertividade, composto por quatro afirmativas sobre aleitamento materno, linguagem, motricidade orofacial e audição. Após o teste de assertividade, foi realizada a dinâmica grupal com as mães, com duração média de vinte minutos, contendo orientações, levantamento de dúvidas e interação sobre aleitamento materno (MEDEIROS AMC, et al., 2015).

Em uma pesquisa realizada com 24 puérperas, divididas em dois grupos de 12, onde o grupo controle recebeu orientações sobre aleitamento materno por meio de palestras e o experimental utilizou simuladores realísticos. Verificou-se que no grupo onde foram aplicados os simuladores realísticos de baixa fidelidade, ocorreu a otimização da aprendizagem sobre o aleitamento materno, possibilitando o autocuidado e reduzindo os problemas que limitavam a amamentação (ABISSULO CMF, et al., 2016).

$\mathrm{Na}$ oficina de atualização, realizada com 236 ACS, mostrou-se eficaz, pois, oportunizou a troca de conhecimentos entre os profissionais e a construção de novos conhecimentos ligados ao tema. Os ACS passaram por uma avaliação antes e depois da oficina, e através do comparativo das notas foi possível identificar que esse período didático influenciou na reformulação de determinadas crenças que existiam entre os agentes, tornando conhecimentos empíricos em conhecimentos científicos (SILVA DRS, et al., 2019).

No processo educativo, em que foi utilizada exposição de cartaz, banners, moldes em formas de mamas exibiu-se como uma possibilidade para a promoção da saúde, possibilitando uma união dos conhecimentos prévios da população com os conhecimentos técnico-científico. Nesse sentindo, oportunizou um ambiente transformador e com troca de informações, que contribuíram para oferta de qualidade de vida para o binômio mãe e filho (RODRIGUES VO, et al., 2018).

\section{Desenvolvimento do Senso Crítico-Reflexivo}

A estratégia nacional de promoção do aleitamento materno valoriza a educação crítico-reflexivo em processos educativos que abordam essa temática. Para tanto, apoia-se um dos seus piares na pedagogia de Paulo Freire (BRASIL, 2015). Fundamento nesse referencial freiriano, o Ministério da Saúde, apresenta a educação transformadora, dentro da estratégia de incentivo ao aleitamento materno, com as seguintes propriedades: dialógica; centrada no educando; valoriza a realidade dos participantes; e incentiva o senso crítico (BRASIL, 2015).

Dentro dessa perspectiva, Freire $\mathrm{P}$ (2018) aborda sobre a superação da educação bancária, que significa o depósito de inúmeros conhecimentos sobre os educandos que são pouco articulado com o contexto em que esses vivenciam. À vista disso, propõe a educação problematizadora, em que a realidade vivenciada pelos educandos é valorizada e também se torna um objetivo de estudo dentro do processo educativo (FREIRE P, 2018). 
Tais propriedades elencadas, foram observadas nos artigos analisados na presente pesquisa, visto que as tecnologias educacionais em saúde, promoveram a prática do aleitamento materno, utilizando uma abordagem dialógica e valorizando o contexto do público-alvo.

Nota-se que a tecnologia educacional musical validada, mostrou-se efetiva no processo de aprendizagem dos alunos na introdução do conteúdo da fisiologia da lactação. A música potencializa aprendizagem e o desenvolvimento do pensamento crítico e reflexivo a partir de uma formação humanizada. Além disso, permite que os participantes do processo educativo ampliem criticamente seus conhecimentos prévios (CHERUBIM DO, et al., 2019).

Semelhantemente, as oficinas educativas, desenvolvidas em um estudo com 105 gestantes, usuárias de um ambulatório de obstetrícia, evidenciou que a roda de conversa é uma tecnologia educacional em saúde que auxilia as participantes a construírem conhecimentos acerca da gestação e a amamentação (NUNES RD, et al., 2019).

A oficina educativa, desenvolvida com os ACS, foi de encontro aos estudos apresentados, uma vez que mostrou-se uma tecnologia educacional em saúde para o desenvolvimento do pensamento crítico-reflexivo, pois essa ação coloca em confronto os conhecimentos de mundo que essas pessoas possuem com 0 conhecimento científico que deveriam possuir (HOPPE AS, et al., 2017).

Na mesma linha de raciocínio das oficinas utilizadas com os ACS, o jogo de tabuleiro manifestou-se uma estratégia com resultados plausíveis para o desenvolvimento do pensamento crítico-reflexivo em crianças. Esse método educativo excita a competitividade e a comunicação dos estudantes, o que incentiva a aprendizagem sobre amamentação (MARTINS FDP, et al., 2018). Os simuladores realísticos de baixa fidelidade foram desenvolvidos com o objetivo de diminuir as principais dificuldades encontrada pelas puérperas, como por exemplo pega inadequada, posição inadequada e fissuras mamilares, que são muito comuns durante esse período de amamentação (ABISSULO CMF, et al., 2016).

Diante dessa perspectiva, a metodologia em questão traz a essas mulheres para uma experiência mais fidedigna do que elas poderão vir a vivenciar em breve, sendo assim pode ser considerada uma boa estratégia para o desenvolver o pensamento crítico-reflexivo (ABISSULO CMF, et al., 2016).

Os estudos analisados mostraram que o uso da tecnologia educativa vem contribuindo com a valorização e ampliação dos conhecimentos prévios, tendo em vista que muitas vezes os meios tradicionais possuem limitações como: propiciar um diálogo entre todos os participantes; e estar de acordo com a realidade dos educandos. Sendo assim, nota-se que as tecnologias educacionais em saúde consideram a realidade dos sujeitos e permitem edificar conhecimentos para serem aplicados em suas respectivas realidades, desenvolvendo o senso crítico-reflexivo.

\section{CONSIDERAÇÕES FINAIS}

O estudo desvelou que as tecnologias educacionais em saúde estão imbricadas no desenvolvimento de processos educativos, facilitando assim o diálogo entre o profissional de saúde e o público-alvo. Propiciaram também um ensino dinâmico e contextualizado com os participantes. Deste modo, exibiram-se resultados favoráveis na promoção e proteção do aleitamento materno. Além disso, pode-se notar que as tecnologias educativas em saúde estão alinhadas ao desenvolvimento de processo de ensino-aprendizagem ativos, visto que propicia a construção de conhecimentos pelos educandos e não a mera transmissão de conhecimentos.

\section{REFERÊNCIAS}

1. ABISSULO CMF, et al. Tecnologias educacionais facilitadoras do conhecimento das puérperas em relação ao aleitamento materno: revisão integrativa. Revista Enfermagem Atual In Derme, 2015; 72(10): 29-36.

2. ABISSULO CMF, et al.Validação de simuladores realísticos para orientação sobre aleitamento materno: pesquisa quase-experimental. Online Brazilian Journal of Nursing, 2016; 15(4): $599-604$.

3. BALBINO AC, et al. O impacto das tecnologias educacionais no ensino de profissionais para o cuidado neonatal. Revista Cuidarte, 2020; 11(2): 1-13.

4. BARBOSA EMG, et al. Tecnologias educativas para promoção do (auto) cuidado de mulheres no pós-parto. Revista Brasileira de Enfermagem, 2016; 69(3): 582-590. 
5. BRASIL. Ministério da Saúde. Secretaria de Atenção à Saúde. Estratégia nacional de promoção do aleitamento materno e alimentação complementar saudável no sistema único de saúde. Ministério da Saúde, 2015. 149p.

6. Brasil - Ministério da Saúde. Secretaria de Atenção à Saúde. Departamento de Ações Programáticas Estratégicas. Atenção à saúde do recém-nascido: guia para os profissionais de saúde. Ministério da Saúde, 2014. 192p.

7. CAPUCHO LB, et al. Fatores que interferem na amamentação exclusiva. Revista Brasileira de Pesquisa em Saúde. Brazilian Journal of Health Research, 2017; 19(1): 108-113.

8. CHERUBIM DO, et al. Tecnologia educativa musical para aprendizagem da fisiologia da lactação: tradução do conhecimento. Revista Brasileira de Enfermagem, 2019; 72(3): 229-236.

9. DODT RCM, et al. Estudo experimental de uma intervenção educativa para promover a autoeficácia materna na amamentação. Revista Latino-Americana de Enfermagem, 2015; 23(4): 725-732.

10. FONSECA LMM, et al. Tecnologia educacional em saúde: contribuições para a enfermagem pediátrica e neonatal. Escola Anna Nery, 2011; 15(11): 190-196.

11. FREIRE P. Pedagogia do oprimido. 65. ed. Rio de Janeiro/São Paulo: Paz e Terra, 2018; 253.

12. FREITAS LA, et al. Avaliação do curso online na educação permanente sobre aleitamento materno para enfermeiros. Revista de Enfermagem UFSM, 2018; 8(1): 116-121.

13. GUIMARÃES DC, et al. Conhecimento da puérpera sobre amamentação na atenção básica. Revista Eletrônica Acervo Saúde, 2018; 18: 1-7.

14. HOPPE AS, et al. O contexto de trabalho de Agentes Comunitários de Saúde: a relação do conteúdo do trabalho com variáveis sociodemográficas. Revista Jovens Pesquisadores, 2017; 7(1): 60-73.

15. JAVORSKI M, et al. Efeitos de uma tecnologia educativa na autoeficácia para amamentar e na prática do aleitamento materno exclusivo. Revista da Escola de Enfermagem da USP, 2018; 52: 1-8.

16. MARTINS FDP, et al. Effect of the board game as educational technology on schoolchildren's knowledge on breastfeeding. Revista Latino-Americana de Enfermagem, 2018; 26: 1-12.

17. MEDEIROS AMC, et al. Aleitamento materno e aspectos fonoaudiológicos: conhecimento e aceitação de mães de uma maternidade. Audiology - Communication Research, 2015; 20(3): 183-190.

18. NUNES RD, et al. Evaluating the effectiveness of an educative workshop for pregnant women using pre and post intervention surveys. Cadernos de saude publica, 2019; 35(10): 1-7.

19. OLIVEIRA PMP, et al. Amamentação: validação de tecnologia assistiva em áudio para pessoa com deficiência visual. Acta Paulista de Enfermagem, 2017; 30(2): 122-128.

20. PAIM JSL, et al. Fatores associados a prática e a duração do aleitamento materno no Brasil contemporâneo. Investigação. Investigação, 2018; 17(3) 66-74.

21. RIBEIRO NM, et al. Construção e validação de folheto educativo para promoção do aleitamento materno e alimentação complementar do lactente, 2018; 18(2): 349-59.

22. RODRIGUES VO, et al. O fazer profissional no codiano: vivências de práticas educativas na prevenção de intercorrências mamárias que incentivam a promoção do aleitamento materno, 2018; 4(4): 147-157.

23. SANTOS AS, et al. Tecnologia educacional baseada em Nola Pender: promoção da saúde do adolescente. Revista Enfermagem UFPE on line, 2018; 12(2): 582-588.

24. SARDINHA DM, et al. Promoção do aleitamento materno na assistência pré-natal pelo enfermeiro. Revista de Enfermagem UFPE on line, 2019; 13(3): 852-857.

25. SILVA DRS, et al. Oficina sobre aleitamento materno com agentes comunitários de saúde: do saber ao aprendizado. Revista Brasileira de Ciências da Saúde, 2019; 23(4): 411-420.

26. TEIXEIRA EM, SOUZA VMS. Tecnologias educacionais em foco. São Caetano do Sul: Difusão Editora, $2011 ; 114$ p.

27. VASCONCELOS MGL, et al. Avaliação de um ambiente digital de aprendizagem pelo usuário. ACTA Paulista de Enfermagem, 2013; 26(1): 36-41.

28. VICTORA CG, et al. Amamentação no século 21: epidemiologia, mecanismos, e efeitos ao longo da vida. Epidemiologia e Serviçoes de Saúde, 2016; 2:1-24. 